\title{
Functional Disability and Their Associated Chronic Diseases among Elderly Patients Attending an Egyptian Family Practice Clinic
}

\author{
${ }^{1}$ Rehab A. Mohamed, 2,3 Doaa M. Abdel-Salam and ${ }^{1}$ Samar F. Mohamed \\ ${ }^{1}$ Family Medicine Department, Faculty of Medicine, Suez Canal University, Ismailia, Egypt. ${ }^{2}$ Public \\ Health and Community Medicine Department, Faculty of Medicine, Assiut University, Assiut, Egypt. \\ ${ }^{3}$ Family and Community Medicine Department, College of Medicine, Jouf University, Aljouf, Saudi \\ Arabia.
}

Submission Date: 17-01-2021 Revision Date: 03-02-2021 Acceptance Date: 03-02-2021

\section{Abstract}

Background: With the enhanced life expectancy, the number of elderly persons is constantly increasing. Functional disabilities increase among elderly persons with the growing burden of chronic diseases leading to dependency and affection of performance of daily activities. Objectives: The present study was carried out to determine the prevalence of functional disabilities among elder of various chronic diseases and disabilities, and the relation between chronic diseases and disabilities. Method: The design of the present study was crosssectional. Data collection was done using a semi-structured anonymous questionnaire. SPSS program, version 24 was used for data analysis. Results: The mean age of the studied participants was 67.19 \pm 5.94 years. Seventy-three percent of the studied participants had three chronic diseases or more. Most of the respondents had diabetes mellitus (62.3\%), hypertension (75.8\%), musculoskeletal pain (61.3\%), and eye diseases (51.7\%). Concerning the prevalence of functional disability, $50.9 \%$ and $49.1 \%$ of the studied participants were independent and partially dependent, respectively. The significant predictors of functional disability were age $>75$ years (odds ratio (OR): 2.06; confidence interval (CI): 1.08-3.91), very low socioeconomic status (OR): 2.64; confidence interval (CI): 2.01-4.80), and number of chronic diseases $\geq 3$ (odds ratio (OR): 9.62; confidence interval (CI): 4.39-21.04). Conclusions: The present study showed a significant association between elderly chronic diseases and disabilities. Furthermore, advanced age and very low socioeconomic status were significant determinants of functional disability among the studied participants. Implementation of geriatric health programs is of vital importance for the screening of chronic diseases and disabilities identification.

Keywords: disability, elderly, chronic diseases, dependence

Corresponding author: Rehab A. Mohamed

Email: drrehabali@yahoo.com

\section{Introduction}

Population aging would be the driving force of the predicted rise in the burden of disease in the elderly, mostly noticeable in low-income, middle-income countries and in diseases that depend highly on age (dementia, stroke, chronic obstructive pulmonary disease, and diabetes). ${ }^{1}$
The global epidemic of chronic diseases is closely related to the aging of the population. In addition to the actual and proportional numbers (comparative to the overall population size) of elderly people ( $\geq 60$ years), diseases with a clear agedependent relationship will rise in prevalence. $^{2}$
The Egyptian Journal of Community Medicine
Vol. 39
No. 4
Oct.
2021 
An important health indicator that points to the jeopardized quality of life is a disability in older people. ${ }^{3}$. Despite the population's aging, medical care has some difficulties in developing methodologies aimed at providing the best care for elderly patients. Although in the traditional disease-oriented model of care, chronic diseases have been the subject of concern, studies show that geriatric impairments are stronger determinants of disability in activities of daily living (ADLs) and nearly as strong for mobility disability. ${ }^{4}$

The International Classification of Functioning, Disability, and Wellbeing (ICF) model of the World Health Organization indicates that clinicians should concentrate on the severe disabilities that result from health problems and on the factors affecting the capacity of the patient to adapt to all those disabilities. $^{5,6}$

Geriatric treatment puts a tremendous strain on the health system and family members as there are a lot of elderly age health conditions and physical disorders. Their functional status is among the main components of elderly patients ' quality of life. This is the capacity of the person to live a comfortable life and to adjust to his / her environment or, for basic human needs, to conduct normal daily activities and to perform normal functions of health and well-being. ${ }^{7}$

One of the strategies to the review of the elderly's well-being is to study their capability in daily living activities (ADLs) or a daily task of self-care that a person must execute, which is a composite measure of the individual's ability to conduct certain fundamental functions. ${ }^{8}$

The disability may be prevented either by the disease being prevented or by the disability being avoided. As the main causes of impairment are chronic illnesses, it is important to determine chronic disorders and their relationship with disability. Egypt like many other countries is undergoing a demographic transition towards an aging society, so such studies will be considered important in Egyptian community. The present study was done to determine the prevalence of functional disability among elderly patients with chronic diseases presenting to the family practice clinic at Suez Canal University Hospital, Ismailia, Egypt.

\section{Method}

Study design and setting: The present study was conducted at the family practice clinic at Suez Canal University hospital, from January 2020 until June 2020. The clinic was chosen for geographic proximity, accommodating clinic environment, established chronic diseases services, its ability to achieve the recruitment rate, to provide a fair representation of the patient population in Ismailia, and for the availability of infrastructure such as patient's records, available resources for patient investigations, referral and follow up.

Sample size and sampling: The sample size was calculated using $\mathrm{n}=\mathrm{P}(1-\mathrm{P}) \mathrm{z}^{2} / \mathrm{d}^{2}$ 9 assuming the prevalence of chronic diseases among the elderly to be $45 \%$ (10) with a precision of 5\%, applying a confidence level of $95 \%$ and $80 \%$ power of the study. The calculated sample size was 385. A systematic random sampling technique was done for selection of the cases. As the total number of patients attending the family practice clinic at $\mathrm{Suez}$ Canal University hospital was 2400 and the sample size was 385 . So, the sampling interval was 6.2. The case was selected every $6^{\text {th }}$ patient if it fulfilled the inclusion criteria.

Inclusion criteria: old age patients 60 years old and above who have any chronic disease. Chronic diseases are long lasting 
conditions with persistent effects and require ongoing medical attention or limit activities of daily living or both. ${ }^{11}$

Exclusion criteria: Elderly patients who refused to participate in the study and who have severe chronic diseases such as cancer in advanced stages rendering a subject's participation in the study nonfeasible.

\section{Data collection tool}

A semi-structured anonymous questionnaire was used to collect the data and was modified according to the results of the pilot study. A pilot study was carried out on 10 elderly patients to assess the significance of the questions to the aim of the work, determine whether the respondents understand them or not, and to determine the time needed to complete the interview. The pilot study findings have not been used in the current study. The questionnaire is composed of four parts. The first part included sociodemographic data, age in years, gender, marital status, and current work. The second part included a scale for measuring family socioeconomic status (SES) for health research in Egypt. ${ }^{12}$ This score includes 7 domains, total score: (out of 84), socioeconomic level: to be classified into very low, low, middle, and high levels depending on the quartiles of the score calculated (Very Low: 1-21), (Low: 2243), (Middle: 44-65), and (High: 66-84). Every enrolled participant was asked about his/her educational and cultural domain, occupation domain, family domain, family possessions domain, economic domain, home sanitation domain, and health care domain. The third part included questions about chronic morbidities among the target population such as hypertension, diabetes mellitus, heart diseases, kidney diseases, liver diseases, stroke, musculoskeletal pain, and eye diseases. The fourth part was the Arabic ADL Scale (13). The Arabic
ADL Scale is a 6-item ordinal scale that measures functional independence in the domains of personal care and mobility. Specifically, it measures self-care, sphincter management, transfers, and locomotion. The Arabic ADL Scale includes six personal activities: bathing, dressing, and undressing getting on and off a toilet, moving from wheelchair to bed and returning, controlling the bladder, controlling bowel, and feeding. The disability inactivity interview questions were described and graded in scale steps $(0,1 / 2,1)$. Based on the Arabic ADL Scale, scores of 0 points indicate very dependent, 1-5 points indicate partially dependent, and 6 points indicate independent.

\section{Data analysis}

Data analysis was done utilizing the SPSS program (SPSS Inc., Chicago, IL, USA), version 24. Quantitative data were expressed as means \pm standard deviation while qualitative data were expressed as frequencies and percentages. Chi-square test was used when qualitative categorical variables were compared. Whenever the predicted values were lower than Five in one or more of the cells in a $2 \times 2$ table, Fisher's exact test was being used. Binary logistic regression analysis was performed to adjust for confounding variables. At pvalue $<0.05$, statistical significance was assumed.

\section{Ethical considerations}

The study was done with the approval of the Research Ethics Committee of Faculty of Medicine Suez Canal University, Egypt (reference number\#4028). The objectives of the study were clarified to the participants and written informed consent was provided from participants who decided to participate in the study. By using anonymous questionnaires, the authors guarantee the privacy and confidentiality of the data obtained. 


\section{Results:}

The sociodemographic characteristics of the respondents is displayed in table 1 . The mean age of the studied participants was 67.19 \pm 5.94 . Most of the respondents were females (55.3\%), currently married $(68.1 \%)$, and non-employed (90.6\%). Also, $57.9 \%$ of the participants had low Table (1): Socio-demographic characteristics of elderly patients attending an Egyptian family practice clinic

\begin{tabular}{lr}
\hline $\begin{array}{c}\text { Socio-demographic } \\
\text { characteristics }\end{array}$ & $\begin{array}{c}\text { No. (\%) } \\
(\mathbf{N}=\mathbf{3 8 5})\end{array}$ \\
\hline Age & \\
$60-64$ & $134(34.8)$ \\
$65-69$ & $140(36.4)$ \\
$70-74$ & $56(14.5)$ \\
$\geq 75$ & $55(14.3)$ \\
Mean $\pm S D$ & $67.19 \pm 5.94$ years \\
\hline Sex & $172(44.7)$ \\
Male & $213(55.3)$ \\
Female & \\
\hline Currently married & $262(68.1)$ \\
Yes & $123(31.9)$ \\
No & \\
\hline Currently employed & $36(9.4)$ \\
Yes & $349(90.6)$ \\
No
\end{tabular}

\section{Socio-demographic}

status

Very low

$104(27.0)$

Low

Middle

$58(15.1)$

Mean $\pm S D$

$29.26 \pm 11.58$

socioeconomic status. The mean score of socioeconomic status was 29.26 \pm 11.58 . Table (2) explored that $73 \%$ of the studied participants had three chronic diseases or more. Most of the respondents had diabetes mellitus (62.3\%), hypertension (75.8\%), musculoskeletal pain (61.3\%), and eye diseases $(51.7 \%)$. Regarding the prevalence of functional disability according to ADL score, $50.9 \%$ and $49.1 \%$ of the studied participants were independent and partially dependent, respectively (figure 1). Regarding the sociodemographic correlates of functional disability. Functional disability was significantly higher among older age $(\mathrm{p}=0.023)$, females $(\mathrm{p}=0.011)$, widowed $(\mathrm{p}=0.035)$, non-employed $(\mathrm{p}=0.002)$, and very low socioeconomic status participants ( $p<0.001)$ (Table 3). Functional disability was significantly higher among participants with three chronic diseases or more $(\mathrm{p}=0.000), \quad$ Table (2): Pattern of self-reported chronic diseases among elderly patients attending an Egyptian family practice clinic

\begin{tabular}{|c|c|}
\hline Chronic diseases & No. $(\%)(n=385)$ \\
\hline $\begin{array}{l}\text { Number of chronic } \\
\text { diseases }\end{array}$ & \\
\hline 1 & $59(15.3)$ \\
\hline 2 & $45(11.7)$ \\
\hline$\geq 3$ & $281(73.0)$ \\
\hline \multicolumn{2}{|l|}{ Diabetes } \\
\hline Yes & $240(62.3)$ \\
\hline No & $145(37.7)$ \\
\hline \multicolumn{2}{|l|}{ Hypertension } \\
\hline Yes & $292(75.8)$ \\
\hline No & $93(24.2)$ \\
\hline \multicolumn{2}{|l|}{ Cardiovascular diseases } \\
\hline Yes & $98(25.5)$ \\
\hline No & $287(74.5)$ \\
\hline
\end{tabular}

\begin{tabular}{lr}
\hline Kidney diseases & \\
Yes & $30(7.8)$ \\
No & $355(92.2)$ \\
\hline Liver diseases & $69(17.9)$ \\
Yes & $316(82.1)$ \\
No & \\
\hline Stroke & $9(2.3)$ \\
Yes & $376(97.7)$ \\
No & \\
\hline Musculoskeletal pain & $236(61.3)$ \\
Yes & $149(38.7)$ \\
No & \\
\hline Osteomalacia & $118(30.6)$ \\
Yes & $267(69.4)$ \\
No & \\
\hline Eye diseases & $199(51.7)$ \\
Yes & $186(48.3)$ \\
No & \\
\hline
\end{tabular}

cardiovascular diseases $(\mathrm{p}=0.003)$, diabetes mellitus $(\mathrm{p}=0.000)$, hypertension $(\mathrm{p}=0.000)$ 
(Table 4). Besides, functional disability was significantly higher among participants who had a stroke $(\mathrm{p}=0.018)$, musculoskeletal pain $(\mathrm{p}=0.002)$, osteomalacia $(\mathrm{p}=0.014)$, and eye diseases $(\mathrm{p}=0.007)$. Logistic regression analysis revealed that age > 75 years, very low socioeconomic status, and the number of chronic diseases $\geq 3$ were significant

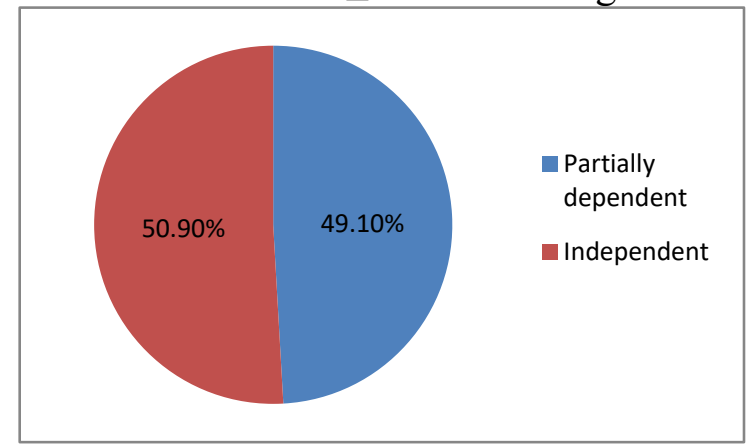

Figure (1): Prevalence of physical disability according to ADL score among elderly patients attending an Egyptian family practice clinic

predictors of functional disability (Table 5). Participants aged $>75$ years were 2.06 times more likely to have a functional disability than those aged 60-64 (odds ratio (OR): 2.06; confidence interval (CI): 1.083.91). Furthermore, participants with very low socioeconomic status were 2.64 times more likely to have a functional disability than participants with middle socioeconomic status (odds ratio (OR): 2.64; confidence interval (CI): 2.01-4.80). The present study also showed that participants with three chronic diseases or more were 9.62 times more likely to have a functional disability than participants with one chronic disease (odds ratio (OR): 9.62; confidence interval (CI): 4.39-21.04).

\section{Discussion}

More older people are at increased risk of disability as the world's population ages steadily, leading to greater demand for healthcare facilities and rising costs of healthcare costs. ${ }^{14}$ The global disease burden among elderly people is expected to rise by the increase in the elderly population, aligned with population aging being one of the most significant elements of the epidemic of chronic disease. ${ }^{15}$

In Egypt, elderly is expected to begin at the age of 60 , and 7.2 percent of the population is considered elderly. ${ }^{16}$ It is estimated that the elderly population in Egypt will increase by 10.9 percent in $2026 .{ }^{17}$

The burden of communicable diseases has fallen because of the epidemiological change, at the expense of a growing burden of chronic diseases. Large vaccine programs initiated in the last few years have helped the transition. ${ }^{18}$ This explains the finding in the present study in which all the respondents reported having one or more chronic diseases and that most of them have 3 or more chronic conditions. In a study in Banha city, Egypt, the authors found that all elderly participants in the studied sample suffered from at least one of the chronic diseases. ${ }^{19}$

In the present study, hypertension, diabetes, and musculoskeletal diseases were found to be the most preventable among the study population. The most prevalent illnesses among the elderly are arthritis and hypertension, as more than one-fifth of them suffer from these diseases in a study carried out by Keshari et al. in India. ${ }^{20}$

Regarding the prevalence of physical disability according to the ADL scale, $49.1 \%$ of the respondents were partially dependent while $50.9 \%$ were independent in the present study and this can be due to the study setting as the study population was recruited from the family practice clinic attendees and it is expected not to find very dependent elderly. Vaish et al. reported that the prevalence of functional disability was found to be $25.6 \%$ in a community bases study in India. ${ }^{21}$ 
Whereas the prevalence of functional disability was 46.8 percent in another community-based research. ${ }^{22}$ The disparity in the prevalence between different studies could be attributed to the fact that different meanings were used by these researchers

Table (3): Association of socio-demographic characteristics and functional disability among elderly patients attending an Egyptian family practice clinic

\begin{tabular}{|c|c|c|c|}
\hline $\begin{array}{c}\text { Socio-demographic } \\
\text { characteristics }\end{array}$ & $\begin{array}{c}\text { Partially dependent } \\
(n=189)\end{array}$ & $\begin{array}{c}\text { Independent } \\
(\mathrm{n}=196)\end{array}$ & P-value \\
\hline $\begin{array}{l}\text { Age } \\
\bullet 60-64 \\
\text { - } 65-69 \\
\text { - } 70-74 \\
\cdot \geq 75\end{array}$ & $\begin{array}{l}58(43.3 \%) \\
63(45.0 \%) \\
33(58.9 \%) \\
35(63.6 \%)\end{array}$ & $\begin{array}{l}76(56.7 \%) \\
77(55.0 \%) \\
23(41.1 \%) \\
20(36.4 \%)\end{array}$ & $0.023^{*}$ \\
\hline $\begin{array}{l}\text { Sex } \\
\text { - Male } \\
\text { - Female }\end{array}$ & $\begin{array}{r}72(41.9 \%) \\
117(54.9 \%)\end{array}$ & $\begin{array}{r}100(58.1 \%) \\
96(45.1 \%)\end{array}$ & $0.011^{*}$ \\
\hline $\begin{array}{l}\text { Marital status } \\
\text { - Married } \\
\text { - Widowed }\end{array}$ & $\begin{array}{r}119(45.4 \%) \\
70(56.9 \%)\end{array}$ & $\begin{array}{r}143(54.6 \%) \\
53(43.1 \%)\end{array}$ & $0.035^{*}$ \\
\hline $\begin{array}{l}\text { Currently employed } \\
\text { - Yes } \\
\text { - No }\end{array}$ & $\begin{array}{r}9(25.0 \%) \\
180(51.6 \%)\end{array}$ & $\begin{array}{r}27(75.0 \%) \\
169(48.4 \%)\end{array}$ & $0.002 *$ \\
\hline $\begin{array}{l}\text { Socio-demographic } \\
\text { status } \\
\text { - Very low } \\
\text { - Low } \\
\text { - Middle }\end{array}$ & $\begin{array}{r}72(69.2 \%) \\
108(48.4 \%) \\
9(15.5 \%)\end{array}$ & $\begin{array}{r}32(30.8 \%) \\
115(51.6 \%) \\
49(84.5 \%)\end{array}$ & $0.000 *$ \\
\hline
\end{tabular}

*Statistically significant

prevalence from 33.5 percent in 2014 to 40.4 percent in $2050 .{ }^{14}$ In the present study, functional disability was significantly higher among older age ( $\geq 75$ years). A similar finding was reported by Gupta et.al ${ }^{23}$ ) and Vaish et.al. ${ }^{21}$

This study showed that disabilities were significantly associated with the female gender, which is similar to other studies conducted in Egypt. ${ }^{24}$

High overall fertility can increase the risk of disability among females in Arab countries, including Egypt. ${ }^{24}$ Also, in their later years, men frequently remain family providers and continue to participate in the labor force. ${ }^{25}$ to describe a functional disability. The steepest increase in ADL impairment was among the oldest age group of elderly people aged 85 and over, with a predicted increase in

the 
functional disability was significantly higher among participants with very low socioeconomic level. This is like the research conducted in Minia, Egypt where disability was associated with age and low income. $^{28}$ Table (4): Association of self-reported chronic diseases and functional disability among elderly patients attending an Egyptian family practice clinic

\begin{tabular}{|c|c|c|c|}
\hline Chronic diseases & $\begin{array}{c}\text { Partially dependent } \\
(\mathrm{n}=189)\end{array}$ & $\begin{array}{c}\text { Independent } \\
(\mathrm{n}=196)\end{array}$ & P-value \\
\hline $\begin{array}{lll}\text { Number of } & \text { chronic } \\
\text { diseases } & & \\
\text { - } 1 & & \\
\text { - } 2 & & \\
\text { - } \geq 3 & & \end{array}$ & $\begin{array}{r}8(13.6 \%) \\
12(26.7 \%) \\
169(60.1 \%)\end{array}$ & $\begin{array}{r}51(86.4 \%) \\
33(73.3 \%) \\
112(39.9 \%)\end{array}$ & $0.000 *$ \\
\hline $\begin{array}{l}\text { Diabetes } \\
\text { - Yes } \\
\text { - } \mathrm{No}\end{array}$ & $\begin{array}{r}140(58.3 \%) \\
49(33.8 \%)\end{array}$ & $\begin{array}{r}100(41.7 \%) \\
96(66.2 \%)\end{array}$ & $0.000 *$ \\
\hline $\begin{array}{l}\text { Hypertension } \\
\text { - Yes } \\
\text { - No } \\
\end{array}$ & $\begin{array}{r}158(54.1 \%) \\
31(33.3 \%) \\
\end{array}$ & $\begin{array}{r}134(45.9 \%) \\
62(66.7 \%) \\
\end{array}$ & $0.000^{*}$ \\
\hline $\begin{array}{l}\text { Cardiovascular diseases } \\
\text { - Yes } \\
\text { - } \mathrm{No} \\
\end{array}$ & $\begin{array}{r}61(62.2 \%) \\
128(44.6 \%)\end{array}$ & $\begin{array}{r}37(37.8 \%) \\
159(55.4 \%)\end{array}$ & $0.003 *$ \\
\hline $\begin{array}{l}\text { Kidney diseases } \\
\text { - Yes } \\
\text { - No }\end{array}$ & $\begin{array}{c}18(60.0 \%) \\
171(48.2 \%)\end{array}$ & $\begin{array}{r}12(40.0 \%) \\
184(51.8 \%)\end{array}$ & 0.213 \\
\hline $\begin{array}{l}\text { Liver diseases } \\
\text { - Yes } \\
\text { - No }\end{array}$ & $\begin{array}{r}35(50.7 \%) \\
154(48.7 \%)\end{array}$ & $\begin{array}{r}34(49.3 \%) \\
162(51.3 \%)\end{array}$ & 0.764 \\
\hline $\begin{array}{l}\text { Stroke } \\
\text { - Yes } \\
\text { - No }\end{array}$ & $\begin{array}{r}8(88.9 \%) \\
181(48.1 \%)\end{array}$ & $\begin{array}{r}1(11.1 \%) \\
195(51.9 \%)\end{array}$ & $0.018 *$ \\
\hline $\begin{array}{l}\text { Musculoskeletal diseases } \\
\text { - Yes } \\
\text { - No }\end{array}$ & $\begin{array}{l}131(55.5 \%) \\
58(38.9 \%)\end{array}$ & $\begin{array}{r}105(44.5 \%) \\
91(61.1 \%)\end{array}$ & $0.002 *$ \\
\hline $\begin{array}{l}\text { Osteomalacia } \\
\text { - Yes } \\
\text { - No }\end{array}$ & $\begin{array}{r}69(58.5 \%) \\
120(44.9 \%)\end{array}$ & $\begin{array}{r}49(41.5 \%) \\
147(55.1 \%)\end{array}$ & $0.014 *$ \\
\hline $\begin{array}{l}\text { Eye diseases } \\
\text { - Yes } \\
\text { - } \mathrm{No} \\
\end{array}$ & $\begin{array}{l}111(55.8 \%) \\
78(41.9 \%)\end{array}$ & $\begin{array}{r}88(44.2 \%) \\
108(58.1 \%)\end{array}$ & $0.007^{*}$ \\
\hline
\end{tabular}

* Statistically significant

more were 3.29 times more likely to have a physical disability than participants with one chronic disease. A correlation between self-reported multimorbidity and functional impairment has also been found in recent studies in India and America; they have found that the multimorbidity

The Egyptian Journal of Community Medicine

Elderly people are more likely to have chronic illnesses. $^{29}$ Usually, physical disorders arise from chronic illnesses. In the current study, a significant positive correlation was observed between multimorbidity and functional disability. Participants with three chronic diseases or . 
America found that the elderly who have any of the 'big four' non-communicable diseases (cardiovascular diseases, cancer, chronic obstructive pulmonary disease, and type 2 diabetes) are at greater risk of being functionally impaired than people without those diseases. ${ }^{29}$ The Non-communicable diseases epidemic has devastating health

Table (5): Logistic regression analysis showing the predictors of functional disability among elderly patients attending an Egyptian family practice clinic

\begin{tabular}{|c|c|c|}
\hline Characteristics & OR (CI 95\%) & P-value \\
\hline \multicolumn{3}{|l|}{ Age } \\
\hline - $60-64$ & 1 & \\
\hline - $\quad 65-69$ & $1.04(0.65-1.68)$ & 0.872 \\
\hline - $70-74$ & $1.82(0.97-3.43)$ & 0.062 \\
\hline - $\quad \geq 75$ & $2.06(1.08-3.91)$ & 0.028 \\
\hline \multicolumn{3}{|l|}{ Sex } \\
\hline - Male & 1 & \\
\hline - Female & $1.17(0.65-2.11)$ & 0.61 \\
\hline \multicolumn{3}{|l|}{ Currently married } \\
\hline - Yes & 1 & \\
\hline - $\quad$ No & $0.73(0.41-1.29$ & 0.28 \\
\hline \multicolumn{3}{|l|}{ Currently employed } \\
\hline - Yes & 1 & \\
\hline - $\mathrm{No}$ & $0.69(0.28-1.69)$ & 0.42 \\
\hline \multicolumn{3}{|l|}{ Socio-demographic status } \\
\hline - Middle & 1 & \\
\hline - Low & $1.56(0.95-5.37)$ & 0.076 \\
\hline - $\quad$ Very low & $2.64(2.01-4.80)$ & 0.000 \\
\hline \multicolumn{3}{|l|}{ Number of chronic diseases } \\
\hline - 1 & 1 & \\
\hline - 2 & $2.32(0.86-6.28)$ & 0.098 \\
\hline - $\quad \geq 3$ & $9.62(4.39-21.04)$ & 0.000 \\
\hline \multicolumn{3}{|l|}{ Diabetes } \\
\hline - $\quad \mathrm{No}$ & 1 & \\
\hline - Yes & $1.45(0.79-2.65)$ & 0.23 \\
\hline \multicolumn{3}{|l|}{ Hypertension } \\
\hline - No & 1 & \\
\hline - Yes & $0.98(0.51-1.87)$ & 0.94 \\
\hline \multicolumn{3}{|l|}{ Cardiovascular diseases } \\
\hline - $\quad$ No & 1 & \\
\hline - Yes & $1.52(0.87-2.64)$ & 0.13 \\
\hline \multicolumn{3}{|l|}{ Stroke } \\
\hline - No & 1 & \\
\hline - Yes & $6.75(0.77-59.03)$ & 0.08 \\
\hline \multicolumn{3}{|l|}{ Musculoskeletal pain } \\
\hline - No & 1 & \\
\hline - Yes & $0.67(0.37-1.21)$ & 0.19 \\
\hline \multicolumn{3}{|l|}{ Osteomalacia } \\
\hline - No & 1 & \\
\hline - $\quad$ Yes & $1.16(0.67-2.02)$ & 0.59 \\
\hline
\end{tabular}

effects and threatens health systems especially in developing countries. Disability raises the financial burden, the likelihood of hospital admission, domestic assistance requirements, the risk of premature mortality, and the quality-of-life declines. ${ }^{31}$ 


\begin{abstract}
Eye diseases
- No

- Yes

The overall predicted \% of the model is $71.7 \%$

The results demonstrate a significant correlation between elderly chronic diseases and disabilities encouraging more potential initiatives and policies to overcome elderly problems.

The potential limitations of the study include its cross-sectional design, which might have resulted in biased observations, particularly in situations in which the disability may have accompanied or even preceded the disease. Furthermore, selfrecall of the information may have added some bias in the results. However, what adds to the study is that all diseases of the elderly included in the study were previously diagnosed and registered in the clinic records.
\end{abstract}

\section{Conclusion and recommendations}

Advanced age, very low socioeconomic status, and an increased number of chronic diseases were found as significant predictors of functional disability among the study participants. Functional disability needs to be early recognized in the elderly population using appropriate methods so that needed approaches can be initiated to enhance the elderly quality of life. Reduction of disabilities among the elderly should be encouraged by implementing geriatric health programs that include chronic disease screening, disabilities identification, and social services to the elderly and their families.

\section{Acknowledgment}

The researchers express their thanks to the administrators of the family practice clinic at Suez Canal University Hospital for their help in carrying out the present study and to all participants for their cooperation.

\section{Conflicts of Interest:}

None declared
1

0.17

\section{References:}

1. Prince $\mathrm{MJ}$, Wu F, Guo Y, Gutierrez Robledo LM, O'Donnell M, Sullivan R, et al. The burden of disease in older people and implications for health policy and practice. Lancet 2015; 385:549-562. DOI: https://doi.org/10.1016/S0140-6736(14)613477

2. Kinsella K, Phillips DR. Global aging: The challenge of success, Population Reference Bureau. Washington DC, Population Bulletin, 2005; 60 (last accessed December 26, 2020).

3. Agrawal A. Disability among the elder population of India: A public health concern. $\mathbf{J}$ Med Soc 2016;3 0:15-19. DOI: 10.4103/09724958.175791

4. Chaudhry SI, McAvay G, Ning Y, Allore HG, Newman AB, Gill TM. Geriatric impairments and disability: the cardiovascular health study. J Am Geriatr Soc 2010;58(9):1686- 1692. DOI: 10.1111/j.15325415.2010.03022.x.

5. Strawbridge WJ, Shema SJ, Cohen RD, Kaplan GA. Religious attendance increases survival by improving and maintaining good health behaviors, mental health, and social relationships. Ann Behav Med 2001; 23(1):6874. DOI: 10.1207/s15324796abm2301_10

6. World Health Organization. Towards a common language for functioning, disability and health: ICF. Geneva, Switzerland: WHO; 2002. (last accessed December 26, 2020).

7. Srivastava MR, Srivastava JP, Gupta P, Sachan B, Bhardwaj P, Choudhary S. Activities of daily livening score and socio demographic profile among elderly in rural and urban areas of Lucknow city. Int $\mathbf{J} \mathrm{Adv}$ Res 2014;2:437-482

8. Sharma S, Thakur M, Kaur S. Assessment of functional status in the performance of activities of daily living amongst elderly in sub urban population of India. Int $\mathbf{J}$ Nurs Educ 2012; 4:94-96.

9. Lwanga, Stephen Kaggwa, Lemeshow, Stanley \& World Health Organization. (1991). 
Sample size determination in health studies: a practical manual / S. K. Lwanga and S. Lemeshow. World Health Organization. https://apps.who.int/iris/handle/10665/4006

2 (Last accessed January 31,2021).

10. Chakrabarty D, Mandal PK, Manna N, et al. Functional Disability and Associated Chronic Conditions among Geriatric Populations in a Rural Community of India. Ghana Med J 2010; 44(4):150-154. DOI:10.4314/gmj.v44i4.68913

11.Australian Institute of Health and Welfare. Chronic Diseases. (2016). Available from: http://www.aihw.gov.au/chronic-diseases/ (last accessed January 31,2021).

12.El-Gilany A, El-Wehady A, El-Wasify M. Updating and validation of the socioeconomic status scale for health research in Egypt. East Mediterr Health J 2012;18(9):962-968. DOI: 10.26719/2012.18.9.962.

13.Ramzi Nasser R. and Jacqueline Doumit J. Validity and reliability of the Arabic version of Activities of Daily Living (ADL). BMC Geriatr 2009; 9: 11. DOI: 10.1186/1471-23189-11.

14.Chen C, Lim JT, Chia NC, Wang L, Tysinger B, Zissimopolous J, Chong MZ, Wang Z, Koh GC, Yuan JM, Tan KB, Chia KS, Cook AR, Malhotra R, Chan A, Ma S, Ng TP, Koh WP, Goldman DP, Yoong J. The Long-Term Impact of Functional Disability on Hospitalization Spending in Singapore. J Econ Ageing 2019; $14 . \quad$ DOI: 10.1016/j.jeoa.2019.02.002.

15. Mathers CD, Loncar D. Projections of global mortality and burden of disease from 2002 to 2030. PLoS Med 2006; 3(11): e442. DOI: 10.1371/journal.pmed.0030442.

16. Aly HY, Hamed AF, Mohammed NA. Depression among the elderly population in Sohag governorate. Saudi Med J 2018; 39(2):185-190.

DOI:10.15537/smj.2018.2.21353

17.El-Sherbiny NA, Younis A, Masoud M. A comprehensive assessment of the physical, nutritional, and psychological health status of the elderly populace in the Fayoum Governorate (Egypt). Arch Gerontol Geriatr 2016; 66:119-126. doi: 10.1016/j.archger.2016.06.001.
18.Rocco L, Tanabe K, Suhrcke M, Fumagalli E. Chronic diseases and labor market outcomes in Egypt - policy research working paper. Washington, DC: The World Bank, 2011. (last accessed December 26, 2020).

19. Shaheen HM, Badr SA, El Sayed Saleh EA. Comparative study between elderly with medical problems living in endwelling houses and with families in Banha City. Menoufia Med J 2017;30:44-50. DOI: $10.4103 /$ mmj.mmj_450_16

20.Keshari P, Shankar H. Prevalence and spectrum of functional disability of urban elderly subjects: A community-based study from Central India. J Fam Community Med 2017; $\quad 24: 86-90 . \quad$ DOI: 10.4103/jfcm.JFCM_80_16

21.Vaish K, Patra S, Chhabra P. Functional disability among elderly: A community-based cross-sectional study. J Family Med Prim Care 2020; 28: 9(1):253-258. DOI: 10.4103/jfmpc.jfmpc_728_19

22. Sowmiya K, Kumar PG, Nagarani. A study on prevalence and correlates of functional disability among the elderly in rural Tamilnadu. Int J Med Res Rev 2015; 3:430-435. DOI: 10.17511/ijmrr. 2015.i4.086

23.Gupta S, Yadav R, Malhotra AK. Assessment of physical disability using Barthel index among elderly of rural areas of district Jhansi (U.P), India. J Family Med Prim Care 2016; 5(4):853-857. DOI: 10.4103/22494863.201178.

24. Obermeyer, C. Islam, Women, and Politics: The Demography of Arab Countries. Population and Development Review 1992; 18 (1), 33-60. DOI:10.2307/1971858

25.Zeinab K . Work and retirement behavior in old age: the experience of older Egyptian men, Egypt. Popul. Fam. Plann. Rev 2003; 36 (2): 19-37

26.Gureje O, Kola L, Afolabi E. Functional disability among elderly Nigerians: Results from the Ibadan study of Ageing. J Am Geriatr Soc 2006; 54:1784-1789. DOI: 10.1111/j.1532-5415.2006.00944.x

27.Pampel FC, and Richard GR. Socioeconomic Status, Smoking, and Health: A Test of Competing Theories of Cumulative Advantage. Journal of Health and Social 
Behavior 2004; 45(3):306-321. DOI: 30.Stenholm S, Westerlund H, Head J, Hyde $10.1177 / 002214650404500305$

28.Mahfouz EM, AwadAllah H. Determinants of disability among elderly population in rural Minia, Egypt. Central European Journal of occupational and environmental medicine 2007; 13(1): 3-15.

29.Fong JH. Disability incidence and functional decline among older adults with major chronic diseases. BMC Geriatr 2019;19 (1):323. DOI: $10.1186 / \mathrm{s} 12877-019-1348-\mathrm{Z}$ M, Kawachi I, Pentti J, Kivimäki M, Vahtera J. Comorbidity and functional trajectories from midlife to old age: the Health and Retirement Study. J Gerontol A Biol Sci Med Sci 2015;70 (3):332-338. DOI: 10.1093/gerona/glu113.

31.Kumar S, Pradhan MR, Singh AK. Chronic diseases and their association with disability among the elderly in India. Social Science Spectrum 2017; 3:27-37. 